\title{
Perspective of Personalized Cancer Therapy
}

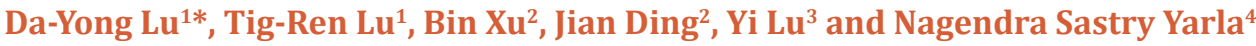 \\ ${ }^{1}$ Shanghai University, China \\ ${ }^{2}$ Shanghai Institute of Materia Medica, Chinese Academy of Sciences, China \\ ${ }^{3}$ Shanghai Ocean University, China \\ ${ }^{4}$ GITAM University, India
}

Submission: June 14, 2017; Published: July 24, 2017

*Corresponding author: Da-Yong Lu, Shanghai University, Shanghai200444, PRC, China, Email: ludayong@shu.edu.cn

Abstract

Personalized medicine is a new frontier in modern medicine. Personalized cancer therapy (PCT) has been developed over 60 years. But, PCT remains to be improved. Central dogma is waiting for uncovering. This perspective addresses this matter briefly.

Keywords: Personalized cancer therapy; Individualized cancer therapy; Drug sensitivity testing; cancer biomarker; Pharmacogenomics; Anti metastatic therapy; Drug combination; Assistant chemotherapy

\section{Introduction}

PCT is imperfect now and in their initial stages due to unsatisfactory clinical outcomes and relatively higher costs in some of the strategies. There are several key factors for these unsatisfactory results. My early gives a panorama of currently applied PCT strategies, especially the drawback of every PCT (individualized cancer chemotherapy, ICC) strategies-drug sensitivity testing (DST), cancer biomarkers, bioinformatics, pharmacogenetics (PG), anti metastatic therapy, drug combination, assistant chemotherapy, cost-effective [1-7]. It serves as a platform or media for discussion and promotion of these ICC strategies.

\section{Which strategy is more powerful?}

DST and PG are the mainstream of current PCT/ICT) $[8,9]$. By analyzing different available PCT/ICT strategies, we suggest the equal importance of every type of ICC strategies by now. Our argument is based on current clinical practice. DST is unsatisfactory now. Patients' survival has improved very little in spite of utilization of DST $[10,11]$. Many factors, such as increasing drug number in the DST, development of more active and specific anticancer or anti metastatic drugs, may ameliorate this condition [10,11]. The more effective and selective anticancer or anti metastatic drugs are developed [12-15], the more favorable outcomes that DST and PG can make because there are better choices of drug armaments $[8,9]$.

Sequencing cancer genomes has gradually increased our power to pinpoint to tumor biomarkers. Detection of human or cancer genetic, transcript, protein or glycoprotein molecular and bioinformatics need less and less moneys in future. The cancer biomarker or bioinformatics detection-based ICT strategy will also update with times and lower cost with technical innovations and might be the most potential ICC strategies in the future [9].

A recent genomic study of $>3,000$ tumors across 26 cancer types has been underway. Only $1 / 4$ of these tumors contain known cancer genes [8]. It means that most tumors are caused by undefined cancer genes. Thus there is a great potential for further investigations of cancer biomarkers.

Now PCT/ICT can be mainly divided into DST, PG and cancer biomarker detection. In future, new disciplines such as individualized anti metastatic chemotherapy and individualized assistant chemotherapy may soon come into reality. The greatest drawbacks of present individualized cancer chemotherapy are designed to target primary tumors rather than metastatic 
lesions. Individualized antimetastatic chemotherapy might be the key of future strategy. We are sure that future trend is to introduce integrated ones of PCT/ICT [9].

\section{Cooperation of all strategies}

A lot of hospitals never try of any ICT strategies. In future, ICT strategies should be improved and perfected for survival benefits or even cure of late stage of cancer patients. The more we try different types of ICT strategies in the clinics, the more satisfactory outcome we may obtain. .

The ultimate goal is to markedly decrease death from cancer. To guide therapeutics, ICT strategies seem to be one of best options for cancer treatment. No matter which type of ICC strategies is used in clinics, it ought to be effective and in reasonable cost. According to this rule, future types of PCT/ICT should combine benefits of all strategy and in reasonable price $[9,16,17]$.

Although much efforts have been made in fulfillment of PCT/ ICT, but many main obstacles still need to be hurdled. For one important reason is there is less improvement in cancer patients' survival in spite of applications of some types of ICC. But it can be a future miracle if we can perfect them into a successful one. So are we ready for that yet? [17].

\section{References}

1. Lu DY (2014) Drug sensitivity testing. In: Lu DY (Ed.), Personalized Cancer Chemotherapy, An Effective Way for Enhancing Outcomes in Clinics. Chapter 2, Woodhead Publishing, Elsevier, UK, pp. 5-12.

2. Lu DY (2014) Individualized cancer chemotherapy via cancer biomarkers or bioinformatics detecting. In: Lu Da-Yong (Ed.), Personalized Cancer Chemotherapy, An Effective Way for Enhancing Outcomes in Clinics. Chapter 3, Woodhead Publishing, Elsevier, UK, pp. 13-20.

3. Lu DY (2012) pharmacogenetics Personalized Cancer Chemotherapy, An Effective Way for Enhancing Outcomes in Clinics. In: Lu Da-Yong (Ed.), Chapter 4, Woodhead Publishing, Elsevier, UK, pp. 21-28.

4. Lu DY (2014) Individualized antimetastatic therapy. In: Lu Da-Yong (Ed.), Personalized Cancer Chemotherapy, An Effective Way for
Enhancing Outcomes in Clinics. Chapter 5, Woodhead Publishing, Elsevier, UK, pp. 29-36.

5. Lu DY (2014) Drug combinations. In: Lu Da-Yong (Ed.), Personalized Cancer Chemotherapy, An Effective Way for Enhancing Outcomes in Clinics. Chapter 6, Woodhead Publishing, Elsevier, UK, pp. 37-42.

6. Lu DY (2014) Assistant chemotherapy. In: Lu Da-Yong (Ed.) Personalized Cancer Chemotherapy, An Effective Way for Enhancing Outcomes in Clinics. Chapter 7, Woodhead Publishing, Elsevier, UK, pp. 43-48.

7. Lu DY (2014) Cost-effectiveness consideration. In: Lu Da-Yong (Ed.), Personalized Cancer Chemotherapy, An Effective Way for Enhancing Outcomes in Clinics. Chapter 8, Woodhead Publishing, Elsevier, UK, pp. 49-59.

8. Lu DY, Lu TR, Chen XL, Ding J (2012) Individualized cancer chemotherapy. In: Shoja MM, Agutter PS, Tubbs RS, Ghanei M, Ghabili $\mathrm{K}$, et al. (Eds.), Hypotheses in Clinical Medicine. Chapter 13, Nova Publisher, US, pp.199-216.

9. Lu DY, Chen XL, Ding J (2006) Individualized cancer chemotherapy integrating drug sensitivity tests, pathological profile analysis and computational coordination-an effective strategy to improve clinical treatment. Medical Hypotheses 66(1): 45-51.

10. Lu DY, Lu TR, Ding J, Xu B, Che JY, et al. (2015) Anticancer drug sensitivity testing, a historical review and future perspectives. Current Drug Therapy 10(1): 44-55.

11. Volm M, Efferth T (2015) Prediction of cancer drug resistance and implications for personalized medicine. Front Oncol 17(5): 282.

12. Lu DY, Lu TR, Cao S (2012) Cancer metastases and clinical therapies. Cell Dev Biol 1(4): e110.

13. Lu DY, Lu TR, Wu HY, Cao S (2013) Cancer metastases treatments. Current Drug Therapy 8(1): 24-29.

14. Valastyan S, Weinberg RA (2011) Tumor metastasis: molecular insights and evolving paradigms. Cell 147(2): 275-292.

15. Lu DY, Lu TR, Xu B, Qi RX, Sastry NY, et al. (2016) Cancer metastasis, a clinical dilemma for therapeutics. Current Drug Therapy 11(2): 163169.

16. Lu DY (2014) Personalized cancer chemotherapy, an effective way for enhancing outcomes in clinics. Woodhead Publishing, Elsevier, UK.

17. Lu DY, Lu TR, Chen XL (2012) Individualized cancer chemotherapy, are we ready for that yet? Metabolomics 2: e113.

\section{Your next submission with Juniper Publishers will reach you the below assets}

- Quality Editorial service

- Swift Peer Review

- Reprints availability

- E-prints Service

- Manuscript Podcast for convenient understanding

- Global attainment for your research

- Manuscript accessibility in different formats

( Pdf, E-pub, Full Text, Audio)

- Unceasing customer service

Track the below URL for one-step submission

https://juniperpublishers.com/online-submission.php 